\title{
A PROBABILISTIC APPROACH TO THE EVALUATION \\ OF THE PTS ISSUE*
}

\author{
R. D. Cheverton \\ D. L. Selby \\ Oak Ridge National Laboratory \\ P.O. Box 2009 \\ Oak Ridge, Tennessee 37831-8047 \\ CONF-910602--13 \\ DE91 009125
}

\section{Abstract}

An integrated probabilistic approach for the evaluation of the pressurized-thermalshock (PTS) issue was developed at the Oak Ridge National Laboratory (ORNL) at the request of the Nuclear Regulatory Commission (NRC). The purpose was to provide a method for identifying dominant plant design and operating features, evaluating possible remedial measures and the validity of the NRC PTS screening criteria, and to provide an additional tool for estimating vessel life expectancy. The approach was to be integrated in the sense that it would include the postulation of transients; estimates of their frequencies of occurrence; systems analyses to obtain the corresponding primary-system pressure, dow'ncomer coolant temperature, and fluid-film heat-transfer cuefficient adjacent to the vessel wall; and a probabilistic fracture-mechanics analysis, using the latter data as input. A summation of the products of frequency of transient and conditional probability of failure for all postulated transients provides an estimate of frequency of vessel failure.

In the process of developing the integrated pressurized-thermal-shock (IPTS) methodology, three specific plant analyses were conducted. These results indicate that the NRC screering criteria may not be appropriate for all U.S. pressurized water reactor

* Research sponsored by the Office of Nuclear Regulatory Research, U.S. Nuclear Regulatory Commission under Interagency Agreement 1886-8011-9B with the U.S. Department of Energy under Contract DE-AC05-84OR21400 with Martin Marietta Energy Systems, Inc.

The submitted manuscript has been authored by a contractor of the U.S. Govermment under Contract No. DE-AC05-84OR21400. Accordingly, the U.S. Government retains a nonexclusive, royalty-free license to publish or reproduce the published form of this contribution, or allow others to do so, for U.S. Government purposes.

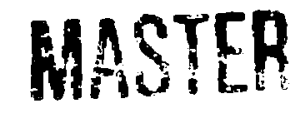


(PWR) plants; that is, for some PWRs, the calculated mean frequency of vessel failure corresponding to the screening criteria may be greater than the maximum permissible value in Regulatory Guide 1.154 .

A recent review of the ORNL IPTS study, which was completed in 1985, indicates that there are a number of areas in which the methodology can and should be updated, but it is not clear whether the update will increase or decrease the calculated probabilities.

\section{Introduction}

The pressurized thermal-shock (PTS) issue is concerned with the possibility of failure of pressurized-water-reactor (PWR) pressure vessels under a very specific set of conditions. These conditions include: (1) the occurrence of reactor transients that subject the vessel to severe thermal shock as well as the normal pressure loading, (2) the existence of sharp, crack-like defects (flaws) at the inner surface of the vessel wall, and (3) high enough fast neutron fluence and concentrations of copper and nickel in the vessel wall to result in an extensive radiation-induced reduction in the fracture toughness of the vessel material. Under these conditions, the mechanism for vessel failure involves propagation of the flaws through the vessel wall, in which case adequate containment of coolant for the core might not be possible. The portion of the vessel of concern is the so-called beltline region because, as shown in Fig. 1, it is directly opposite the core (high fluence rate), it is adjacent to the coolant downcomer (potential for thermal shock), and coolant leakage in this area would tend to uncover the cuice.

The behavior of flaws in reactor pressure vessels under pressure and thermal-shock loading conditions has been under investigation since 1967 by the reactor vendors and as a part of the Heavy-Section Steel Technology (HSST) Program, ${ }^{1}$ which is sponsored by the 
United States Nuclear Regulatory Commission (USNRC). In recent years (1978-1981), HSST vessel-integrity studies ${ }^{2}$ related to postulated and actual PWR PTS transients indicated that if such transients occurred late in the life of a high-copper vessel containing appropriate flaws, the chances of vessel failure could be high. However, these analyses were of a deteminnistic nature and were believed to be quite conservative - that is, they assumed a combination of a very severe PTS transient, high concentrations of copper, lower-bound fracture-toughness data, and the existence of flaws of appropriate size.

Because of the apparent conservative nature of the analytical approach, it was generally believed that the probability of vessel failure was actually very small. To obtain a better understanding of the nature and magnitude of the problem, the NRC proposed the development of a comprehensive probabilistic approâch and in May 1981 established the Integrated Pressurized Thermal-Shock (IPTS) Program, which was managed by the Oak Ridge National Laboratory (ORNL). Not long thereafter (December 1981), the poterial PTS problem was declared an NRC unresolved safety issue, and by July 1985 an NRC PTS Rule was issued. ${ }^{3}$

Results of the IPTS program played an important role in the formulation of the PTS rule, and at this time some PWR vessels are within a few years of violating screening criteria included in the PTS Rule. Thus, a review of the IPTS Program, particularly as it relates to the PTS Rule, appears appropriate and is the purpose of this paper.

\section{Scope of IPTS PTogram}

The scope of the IPTS Program included: (1) the development of a methodology and models for estimating the probability of vessel failure and the uncertainty in the estimate, (2) an estimate of the probability of failure of the reactor pressure vessels in three specific 
commercial PWR plants selected for evaluation, and (3) an assessment of the effects of proposed remedial measures to reduce the potential of PTS-induced vessel failures.

Estimating the probability of failure of the three PWR vessels involved: (1) postulation of PTS transients, (2) an estimate of their frequencies, (3) a systems analysis of each transient to determine corresponding temperatures and pressures, (4) a probabilistic fracture-mechanics analysis that uses the results of the systems analysis as input, and (5) an uncertainty analysis that required combining uncertainties across multiple disciplines.

The probabilistic fracture-mechanics analysis provides an estimate of the conditional probability of vessel failure $[\mathrm{P}(\mathrm{F} \mid \mathrm{E})]$. This estimate can be multiplied by the expected frequency of the corresponding transient $[\Phi(E)]$, and these products, for all postulated transients, can be summed to obtain the total estimated frequency of vessel failure $[\Phi(F)]$ for a specific plant. The individual products are also of interest because they help indicate the extent to which individual transients contribute to $\Phi(F)$.

The scope of the IPTS program included a determination of whether or not, for a given set of conditions, a flaw would completely penetrate the vessel wall. It did not, however, include an evaluation of the extent of subsequent damage to the vessel in the event that the flaw did penetrate the wall. This latter task was the responsibility of Pacific Northwest Laboratories (PNL). Results of their study ${ }^{4}$ indicate that for those transients that contributed significantly to $\Phi(F)$, the probability of a large enough opening to preclude cooling of the core was greater than $50 \%$. Thus, no distinction is made in this paper between through-wall cracking and a "catastrophic" failure.

Before the IPTS Program was established, the NRC, with the help of ORNL and others, estimated the frequency of vessel failure as a function of accumulated radiation 
damage, which is characterized by a material property referred to as the nil ductility reference temperature (RTNDT). (RTNDT is a function of material chemistry and fast-neutron fluence and can be calculated by using empirically derived correlations.) On the basis of these studies, the NRC adopted screening criteria in the form of critical values of RTNDT. If it appears that the critical value will be reached before the vessel design end-of-life is achieved, the operating utility may choose to perform a detailed specific-plant analysis, as described briefly herein, in an effort to justify operation beyond the point in time at which the specified critical value of RTNDT is reached. For this purpose, the NRC has specified a limiting value of $\Phi(F) .5$ Therefore, another objective of the IPTS Program was to investigate the consistency of the NRC-imposed screening criteria and limiting value of $\Phi(F)$.

The three PWR plants (nuclear steam supply systems) evaluated as a part of the IPTS Program were: (1) Oconee-1, designed by Babcock and Wilcox, Inc. and operated by Duke Power, (2) Calvert Cliffs-1, designed by Combustion Engineering, Inc. and operated by Baltimore Gas and Electric; and (3) H. B. Robinson-2, designed by Westinghouse Electric Corporation and operated by Carolina Power and Light. These plants not only represent each of the three PWR-vendor types but were selected out of a group of plants considered by the NRC to have a potential PTS problem.

The methodologies developed for the specific-plant analyses and the results for the three plants considered in the IPTS studies are documented in Refs. 6, 7, and 8 and are discussed briefly in this paper. The three plants were evaluated in series, Oconee being first and H. B. Robinson last, although the publication dates for Refs. 6, 7, and 8 do not reflect this order. There was a significant learning process with Oconee, and as a result the Oconee study is not completely consistent with the other two, and the uncertainty in the Oconee results is relatively large. 
As the study for H. B. Robinson developed, it became apparent that the potential for vessel failure was much less than had been expected, making it a poor choice for demonstrating the probabilistic fracture-mechanics methodology. Thus, a hypothetical plant, identical to H. B. Robinson, with the exception of the vessel-material chemistry, was created for the study and is referred to as HBR-HYPO. The chemistry was altered so that the PTS-Rule screening criteria were reached at 32 EFPY.

\section{Fracture Mechanics}

\subsection{Deterministic model}

The behavior of flaws in the reactor pressure vessel can be evaluated by applying the theory of fracture mechanics, ${ }^{9}$ which characterizes conditions at the tip of the crack by means of a stress-intensity factor $\left(\mathrm{K}_{\mathrm{I}}\right)$ that increases with increasing load (stress) and size of the flaw. In addition, a critical value exists for a given material and temperature at which propagation of the flaw will take place $\left(\mathrm{K}_{\mathrm{IC}}\right)$. At another critical value $\left(\mathrm{K}_{\mathrm{Ia}}\right)$, a fast-running crack will arrest.

$\mathrm{K}_{\mathrm{Ic}}$ and $\mathrm{K}_{\mathrm{Ia}}$, which constitute fracture-toughness properties of the material, are measured in the laboratory over a range of temperatures and fast-neutron fluences. Both $\mathrm{K}_{\mathrm{Ic}}$ and $\mathrm{K}_{\mathrm{Ia}}$ increase with increasing temperature and decrease with increasing fast-neutron fluence. In a reactor pressure vessel, the fast-neutron fluence decreases with increased depth in the wall (Fig. 2). In addition, during a thermal-shock transient, a positive gradient in temperature occurs through the wall because of the rapid cooling of the inner surface. Thus, during PTS transients, positive gradients in fracture toughness occur in the wall of the vessel, and positive gradients favor the propagation of shallow inner-surface flaws and the arrest of an initially shallow fast-running flaw. 
A positive gradient also tends to occur in $\mathrm{K}_{\mathrm{I}}$, and for a given thermal transient, the higher the pressure, the steeper the gradient and the smaller the chances of crack arrest. Thermal shock alone will not drive the flaw completely through the wall, but a full-pressure PTS transient can. Thermal shock alone, however, can drive a flaw deep enough into the wall so that the vessel would not be usable thereafter without repair.

A deterministic fracture-mechanics analysis involves the calculation of $\mathrm{K}_{\mathrm{I}}$ and then a comparison of $\mathrm{K}_{\mathrm{I}}$ with $\mathrm{K}_{\mathrm{Ic}}$ to determine whether propagation will take place; if it does, $\mathrm{K}_{\mathrm{I}}$ is compared to $\mathrm{K}_{\mathrm{Ia}}$ to see if arrest will take place. By repeating this process for a range of crack depths and a number of times in the transient, it is possible to determine whether failure of the vessel will occur, that is, whether the flaw will completely penetrate the wall.

The quantity $\mathrm{K}_{\mathrm{Ic}}$ is measured under a specific set of loading conditions and is intended to represent the minimum fracture-toughness of the material. During PTS transients, loading conditions can exist that result in higher values. For instance, when the derivative of $\mathrm{K}_{\mathrm{I}}$ with respect to time $\left(\dot{\mathrm{K}}_{\mathrm{I}}\right)<0$, the onset of crack propagation will not take place even though $\mathrm{K}_{\mathrm{I}}>\mathrm{K}_{\mathrm{Ic}}$, and, if following a period of $\dot{\mathrm{K}}_{\mathrm{I}}<0 \mathrm{~K}_{\mathrm{I}}$ again increases with time $\left(\dot{K}_{I}>0\right)$, the effective fracture toughness will be considerably greater than $\mathrm{K}_{\mathrm{Ic}}$. These beneficial effects, which are generally referred to as warm prestressing (WPS), were not included in the IPTS studies, except to evaluate the effect of no flaw propagation with $\dot{\mathrm{K}}_{\mathrm{I}}<0$. They were omitted because of uncertainties regarding details of the hypothetical transients and because of a lack of appropriate fracture-toughness data.

As previously mentioned, $\mathrm{K}_{\mathrm{Ic}}$ and $\mathrm{K}_{\mathrm{Ia}}$ are functions of temperature and fluence, and the effect of fluence is a function of the concentrations of copper and nickel. The specific relations used in the IPTS studies for fracture toughness and the effect of neutron radiation 
thereon are basically those included in the ASME Code and USNRC regulatory guides as discussed in Refs. 6,7, and 8. They have the form

$$
\begin{aligned}
& \mathrm{K}_{I c}=\mathrm{f}_{1}(\mathrm{~T}-\mathrm{RTNDT}) \\
& \mathrm{K}_{\mathrm{Ia}}=\mathrm{f}_{2}(\mathrm{~T}-\mathrm{RTNDT}) \\
& \mathrm{RTNDT}=\mathrm{f}_{3}\left(\mathrm{RTNDT}_{\mathrm{O}}, \mathrm{F}, \mathrm{Cu}, \mathrm{Ni}\right),
\end{aligned}
$$

and the attenuation of the fluence through the wall was approximated with

$$
F=F_{0} e^{-0.0094 a,}
$$

where

$$
\begin{aligned}
\mathrm{T} & =\text { temperature } \\
\operatorname{RTNDT}_{\mathrm{O}} & =\text { initial (zero fluence) value of RTNDT } \\
\mathrm{F} & =\text { fast neutron fluence at tip of flaw } \\
\mathrm{F}_{\mathrm{O}} & =\text { fast neutron fluence at inner surface } \\
\mathrm{Cu} & =\text { concentration of copper } \\
\mathrm{Ni} & =\text { concentration of nickel } \\
\mathrm{a} & =\text { flaw depth }(\mathrm{mm})
\end{aligned}
$$

Significant uncertainties are assocjated with each of the above parameters, as well as with the number and size of surface flaws. Thus, even if it is assumed that a particular PTS transient occurs, a probabilistic approach to the evaluation of vessel integrity is appropriate.

\subsection{Probabilistic model}

The conditional probability of vessel failure was calculated with the OCA-P code, 10,11 a fracture mechanics code developed specifically for application to reactor pressure vessels. OCA-P accepts as input, among other parameters, the primary system pressure, the temperature of the coolant in the reactor-vessel downcomer, and the fluid-film 
heat transfer coefficient adjacent to the vessel wall, all as a function of time in a specified PTS transient. The code then performs one-dimensional thermal and stress analyses for the vessel wall and finally a probabilistic fracture-mechanics analysis.

The probabilistic model is based on Monte Carlo techniques; that is, a large number of vessels is generated, and each vessel is then subjected to a deterministic fracture-mechanics analysis to determine whether the vessel will fail. Each vessel is defined by randomly selected values of several parameters that are judged to have significant uncertainties associated with them. The calculated probability of vessel failure is simply the number of vessels that fail divided by the total number of vessels generated. It constitutes a conditional probability of failure $[\mathrm{P}(\mathrm{F} \mid \mathrm{E})]$ because the assumption is made that the PTS transient (event) takes place.

The parameters simulated for the IPTS studies were flaw depth (a), the fast-neutron fluence at the inner surface of the vessel $\left(\mathrm{F}_{\mathrm{O}}\right), \mathrm{RTNDT}$, the concentration of copper in the vessel wall $(\mathrm{Cu})$, and the fracture toughness $\left(\mathrm{K}_{\mathrm{Ic}}\right.$ and $\left.\mathrm{K}_{\mathrm{Ia}}\right)$. Normal distributions were assumed for all of these parameters except flaw depth.

All flaws considered were inner-surface flaws normal to the surface and oriented in either an axial or circumferential direction. With regard to surface length of the flaws, it was assumed that: (1) circumferential flaws were contiruous, (2) axial flaws in axial welds were equal in length to the height of a shell course ( $2 \mathrm{~m})$, and (3) axial flaws in the base material were effectively infinitely long. These assumptions are appropriate for plate-type vessels with staggered axial welds (Fig. 3) and with lower toughness in the welds than in the base material, provided that the cladding on the inner surface does not inhibit surface extension of initially short flaws. (The possible restraining effects of cladding were not included in the IPTS studies, and the fracture toughness of the cladding was assumed to be 
the same as that for the base material. However, cladding was included as a discrete region in the analysis so that thermal and stress effects could be included. Cladding restraining effects are presently under investigation. $12,13,14$ )

The probability of having a flaw with a depth in a specific range of crack depths $\Delta a_{i}$ is given by

$$
F(\Delta a)_{i}=N A \int_{\Delta a_{i}} f(a) B(a) d a,
$$

where

$\mathrm{N}$ = number of surface flaws of all depths per unit surface area,

$A=$ surface area,

$f(a)$ = flaw-depth density function,

$\mathrm{B}(\mathrm{a})=$ probability of nondetection.

The parameters $\mathrm{N}$ and $\mathrm{f}(\mathrm{a})$ pertain to vessel conditions prior to preservice inspection and repair, and $\mathrm{B}(\mathrm{a})$ is derived on the basis of repairing or otherwise disposing of all detected flaws.

The value of $\mathrm{N}$ and the functions $\mathrm{f}(\mathrm{a})$ and $\mathrm{B}(\mathrm{a})$ are not well known because most of the available inspection data do not pertain to surface flaws that extend into and through the cladding of a PWR pressure vessel. For the IPTS studies, the functions $\mathrm{f}(\mathrm{a})$ and $\mathrm{B}(\mathrm{a})$ were those suggested in the Marshall report ${ }^{15}$ and are as follows:

$$
\begin{aligned}
& f(a)=0.16 e^{-0.16 a}, \\
& B(a)=0.005+0.995 e^{-0.113 a},
\end{aligned}
$$


where

$$
\begin{aligned}
& a=\text { crack depth, } m m \\
& \int_{0}^{\infty} f(a) d a=1 .
\end{aligned}
$$

To account for spacewise variations in the parameters simulated, the beltline region was divided into sections that were defined by unique combinations of fluence, chemistry, and the initial value of RTNDT. The flaw surface density was assumed to be the same for each section and equal to 0.2 flaws $/ \mathrm{m}^{2}$. This value is consistent with a flaw density suggested in Ref. 15.

As mentioned above, the calculated probability of vessel failure for this study was the number of simulated vessels calculated to fail divided by the total number of vessels simulated or otherwise accounted for. Thus

$$
P(F \mid E) \cong \sum_{j} \frac{N_{f j}^{\prime}}{N_{v j}^{\prime}} A_{j} N \int_{0}^{w} f(a) B(a) d a,
$$

where

$$
\begin{aligned}
& N_{f j}^{\prime}=\text { number of vessels that will fail with a flaw in the jth section, } \\
& N_{v j}^{\prime}=\text { number of vessels simulated with a flaw in the jth section, } \\
& A_{j}=\text { surface area of jth section, } \\
& w=\text { wall thickness. }
\end{aligned}
$$

For very small values of $P(F I E)$, ihe value of $N_{v j}^{\prime}$ required to achieve reasonable accuracy becomes quite large. Under some circumstances the value of $\mathrm{N}_{\mathrm{vj}}^{\prime}$ can be reduced by using importance-sampling techniques. This was done in some cases by sampling only the tails 
of certain distribution functions. The portion of the distribution function not sampled is accounted for by multiplying the number of simulated vessels, $\mathrm{N}_{\mathrm{vj}}^{\prime}$, by a correction factor.

\subsection{Resuits of probabilistic analysis}

As an example of a PWR-vessel probabilistic fracture-mechanics analysis, reference is made to the Calvert Cliffs Unit 1 IPTS study. ${ }^{7}$ Data pertaining to the sections of the vessel considered are included in Table 1, and calculated values of $P(F \mid E)$ vs number of effective full-power years (EFPY) for the five most dominant transients are shown in Fig. 4. The section of the vessel contributing the most to $P(F \mid E)$ was axial weld 2-203A, and the fluence and RTNDT values corresponding to this weld are included as "independent" variables along with EFPY in Fig. 4. As indicated in Fig. 4, P(F|E) at the plant-design end of life (32 EFPY) ranges from $2 \times 10^{-7}$ to $4 \times 10^{-3}$, and the RTNDT screening criterion of $132^{\circ} \mathrm{C}\left(270^{\circ} \mathrm{F}\right)$ is achieved at $41 \mathrm{y}$. (The screening criterion specified by the NRC is the mean value plus two standard deviations, and for this case $2 \sigma=23^{\circ} \mathrm{C}$.) The contributions of the plate and circumferential-weld sections were cransient dependent and were greatest for transient 8.3. For this transient the circumferential welds contributed $\sim 5 \%$ and the plate sections $\sim 50 \%$. For transient 8.2 , which was the biggest contributor to $\Phi(F)$, the plate contribution was only $5 \%$.

When vessel failure was calculated to take place for the dominant transients, the failure was usually the result of a single long crack jump, and - $-90 \%$ of the critical flaw depths

were in the range 4-14 mm. As mentioned earlier, effects of warm prestressing with $\dot{K}_{1} \leq$ 0 were not included in the final prediction of failure rate. However, the effect was investigated and was found to be very transient dependent. For instance, for transient 8.2 the inclusion of WPS reduced P(FIE) by more than a factor of $10^{3}$, while for 8.3 the effect was negligible. The net effect on $\Phi(F)$ was a factor of $\sim 4$. 


\section{Identification and Frequency of Transients}

Postulation of transients to be considered in the IPTS analysis began with the identification of plant states that could constitute overcooling conditions. Initiating cvents were then identified that could lead to these plant states. Categories of initiating evenis that were identified included

1. Loss-of-coolant accident (LOCA): three rupture sizes and two plant states (zero power and full power);

2. Steam line breaks: two sizes, two locations (upstream and downstream of main steam lir.e isolation valves) and two plant states (zero povier and full power);

3. Overfeed: two plant states (zero power and full power) and three types (single loop, multi-loop, and delayed); and

4. Steam generator tube ruptures (a special LOCA case): two types (single-tube and multi-tube) and two plant states (zero power and full power).

These initiators cover the categories of all potential direct overcooling initiators. Other categories of initiators were identified that could result in overcooling events but in a less direct manner. These categories included

1. Normal reactor trip,

2. Electrical supply system failures,

3. Instrument air system failures, and

4. Component and service water system failures.

After defining the categories of initiators, an event tree was constructed for each initiator to represent the series of potential paths that could develop from the initiating event. Paths in the event tree represented equipment success, partial failure, or complete failure as well as the operator's role and the potential for his failure to perform as required. 
Evaluations of potential equipment states and reviews of operating procedures were used to help structure the trees. Paths for recovery from equipment failures were not placed directly on the event trees. However, the probabilities for such recoveries were included in the probability for the success path, when the recovery was timely enough to preclude the consequences of the failure. Using plant-specific, vendor-specific, and/or generic PWR data, probabilities of equipment failures were assigned to each branch of a tree, and the frequency of each path end point was calculated, considering these probabilities and the frequency of the initiator.

In addition to the nominal failure probabilities, three types of common-cause failures were identified and used to adjust branch-path probabilities when necessary. Commoncause failure of identical pieces of equipment was accounted for by increasing the failure probability for subsequent failures, given the initial component failure. For example, one valve might be considered to fail one in a hundred times, but, given the failure of one valve, a second valve was assumed to fail one out of every ten times. The actual increase in failure probability for subsequent failures, given one failure, was dictated by data collected from plants, the literature, and licensee event reports.

The second type of common cause considered dealt with failures that were expected because of conditions that developed from an mitial failure (these are sometimes called cascading events). In this analysis, three types of initiators were identified as leading to conditions that could create multiple component failures: (1) component cooling failures, (2) instrument air failures, $\operatorname{ar} 3$ (3) electrical supply failures. Results of an extensive analysis of the impact of failures in these three systems indicated that some event-tree paths that were considered to have very low probabilities were in fact much more probable because of 
the potential common-cause interaction. The event-tree-path probabilities were adjusted as required to reflect this understanding.

The third type of common cause dealt with human errors. It was determined that there was a moderately high coupling between operator performances during successive steps of a procedure. Therefore, when a failure of one operator action was identified, the probability of failure to perform succeeding tasks was greatly increased. Dependency factors for the adjustment of the probabilities were taken from Ref. 16.

Although plant operating data were used to a large extent to obtain estimates of ficquencies for initiating events and component failures, there are substantial uncertainties in the frequencies. The distributions associated with these unceriainties were included in an uncertainty analysis that considered "all" parameters that were not simulated in the probabilistic fracture-mechanics analysis. The methodology for and results of this uncertainty analysis are discussed later in this article.

In all three plant analyses, the event trees produced hundreds of thousands of potential overcooling paths. Because of cost and time considerations, it was necessary to reduce the number of specific paths to be analyzed, and this had to be accomplished without losing any of the potential contributions to the integrated probability of vessel failure. Branches with frequencies less than $10^{-7}$ were combined into one or more groups (residual groups) that were intended to contribute little to the overall frequency of failure $(<5 \%)$ and therefore could be treated conservatively as groups rather than as individual transients for the remainder of the analysis.

Approximately 200 patins had individual frequencies greater than $10^{-7}$. These paths and the residual groups were subjected to detailed thermal/hydraulic and then fracture-mechanics analyses to obtain an estimate of the conditional probability of vessel failure. 
The systematic approach described above for postulating and quantifying PTS transients and the very large number of event-tree end points defined ( 130,000 for the reactorshutdown trees alone) tend to provide assurance that transients contributing significantly to $\Phi(F)$ were not overlooked. Of course, not all possible transients were considered. For instance, operator misdiagnusis and error were not included. In addition, although coupled failures were identified for most equipment, only three types of cascading events were considered. Even so, it is believed that the inclusion of these categories of PTS transients would not substantially increase the calculated value of $\Phi(F)$.

\section{Themal/Hydraulic Analyses}

Both RELAP517,18 and TRAC19,20 were used to perform detailed therma// hydraulic analyses of the postulated PTS events for the three plants. More sophisticated versions of these codes were developed at LANL and INEL with the help of nuclear plant and vendor personnel for use in the IPTS studies. The codes were quality-assured in several ways, including comparing the calculated results with measured plant data. It is believed that the results obtained with these codes are reasonable estimates of plant behavior, given the postulated transients and related equipment and operator-action assumptions.

Because of the large number of paths identified in the event trees, it was not practical to consider performing full-scale TRAC or RELAP5 calculations for each sequence. On the other hand, it was felt that some thermal/hydraulic data should be generated for each potential path, even if the cooldown rate was believed to be relatively slow. Therefore, the approach used was to select 10-15 representative sequences for each plant for detailed analysis and then use the resulting data, either directly or in conjunction with simplified models, to estimate the thermal/hydraulic characteristics of the other sequences. 
Two factors were identified as requiring special attention: (1) mixing of emergency core coolant in the cold-leg/downcomer regions, and (2) the heat-transfer coefficient at the surface of the reactor vessel wall in the downcomer region. The mixing analysis was particularly important because of concem regarding the formation of cold plumes in the downcomer region. Such plumes may have temperatures much lower than the bulk average fluid temperature. To properly evaluate the degree of mixing, calculations were performed with the Purdue Regional Mixing Model ${ }^{21}$ and the computer code REMIX, 22 and data from experiments performed at the CREARE 1/5-scale facility 23 and at the Purdue 1/2-scale PTS facility ${ }^{21}$ were considered. In addition, a SOLA-PTS mixing analysis was performed at LANL. ${ }^{24}$ It was determined that plume formation could occur under certain conditions. For these cases, the colder plume temperatures, as estimated by the mixing codes, were used in a one-dimensional heat-transfer analysis of the vessel wall.

\section{Integration of Results}

Vessel failure frequencies were obtained for the various sequences by multiplying the conditional failure probabilities by the corresponding sequence (PTS transient) frequencies. The resulting failure frequencies for all of the sequences were then summed to obtain a total frequency of vessel failure for each of the three plants. The "best-estimate" integrated vessel failure frequency $[\Phi(F)]$ for each plant was less than $5 \times 10^{-6}$ for the design end-of-life condition (Fig. 5). 


\section{Sensitivity and Uncertainty Analyses}

As mentioned earlier, a number of parameters in the above probabilistic analy'sis, which provided what is referred to herein as a best-estimate value of $\Phi(F)$, were not simulated. To account for uncertainties in the frequency of initiating events, event-tree branch probabilities, primary-system pressure, downcomer coolant temperature, flaw density, and the mean values of the fracture-mechanics parameters $\mathrm{KI}_{\mathrm{Ic}}, \mathrm{RTNDT}_{\mathrm{O}}$ and $\triangle \mathrm{RTNDT}$, distributions were assigned to each of these parameters, sensitivity studies were conducted to determine the relation between the fracture-mechanics parameters and $P(F \mid E)$, and, using this information and a response surface, a Monte Carlo analysis was performed that provided adjusted values of $\Phi(F)$ and a distribution (relative frequency of failure vs frequency of failure) such as that shown in Fig. 6. For HBR-HYPO, the adjusted mean value of $\Phi(\mathrm{F})$ corresponding to $\mathrm{RTNDT}(2 \sigma)=132^{\circ} \mathrm{C}\left(270^{\circ} \mathrm{F}\right)$ is $8 \times 10^{-6}$ compared to the "best-estimate" value of $1.4 \times 10^{-8}$. For Calvert Cliffs, the corresponding values are $6 \times 10^{-6}$ and $1.7 \times 10^{-7}$. The best-estimate value for Oconee is $6 \times 10^{-6}$. An uncertainty analysis was not performed for Oconee, but based on the results for the other two plants, the mean value of $\Phi(F)$ is estimated to be $-5 \times 10^{-5}$. [As mentioned earlier, because Oconee was the first plant analyzed, the best-estimate value of $\Phi(F)$ for Oconee is relatively uncertain and does not reflect the same level of understanding and confidence that is associated with the other two studies.]

As indicated above, the comparison of values of $\Phi(F)$ was made for $\operatorname{RTNDT}(2 \sigma)=$ $132^{\circ} \mathrm{C}\left(270^{\circ} \mathrm{F}\right)$, which is the mean value plus two standard deviations at the inner surface of the region of the vessel that contributed the most to $\Phi(F)$. It corresponds to 32 EFPY for HBR-HYPO, 41 EFPY for Calvert Cliffs, and 35 EFPY for Oconee. As indicated earlier 
and discussed later, this value of RTNDT has special significance with regard to an NRCimposed limit on vessel lifetime.

\section{Dominant Transients}

The dominant transients [those that contribute the most to the calculated value of $\Phi(F)]$ for each of the three plants are different, as indicated in Table 2. For Oconee, reactor trips from full power, followed by a secondary-side component malfunction, account for $42 \%$ of $\Phi(\mathrm{F})$; for Calvert Cliffs, $91 \%$ is the result of small-break LOCAs at hot zero power; and for HBR-HYPO, reactor trips account for $88 \%$. [The residuals in Table 2 include many types of transients with a total contribution to $\Phi(F)$ of $\leq 5 \%$.]

\section{Relationship of IPTS Program to the NRC PTS Rule}

The NRC PTS Rule (Code of Federal Regulations 10 CFR 50.61) imposes limits of $132(270)$ and $149^{\circ} \mathrm{C}\left(300^{\circ} \mathrm{F}\right)$ on RTNDT $(2 \sigma)$ for, respectively, the most sensitive axiallyand circumferentially-oriented welds in the beltline region of the vessel, unless additional life of the vessel (a larger value of RTNDT) is justified. These limits on RTNDT are referred to as screening criteria, and as stated in NRC Regulatory Guide 1.154, an acceptable methodology for evaluating the feasibility of operation beyond these limits is a plantspecific study similar to that described in this paper and Refs. 6, 7, and 8. The Regulatory Guide also specifies a maximum permissible value of $5 \times 10^{-6}$ failures/reactor year for the mean value of $\Phi(F)$. Thus, presumably the screening criteria should correspond to $\Phi(\mathrm{F})_{\text {mean }} \leq 5 \times 10^{-6}$.

The screening criteria were derived before the IPTS program was completed and thus without the benefit of this specific study. As indicated in a previous section, the mean values of $\Phi(F)$ for HBR-HYPO and Calvert Cliffs are only slightly above $5 \times 10^{-6}$, but the 
relatively rough estimate for Oconee is a factr- of $\sim 10$ higher. Furthermore, it was determined that small differences in plant design anu _perating procedures could have a substantial effect on calculated values of $\Phi(F)$. This suggests that even though the screening criteria appear to be appropriate for Calvert Cliffs and H. B. Robinson, similar plants might have substan ially higher values of $\Phi(F)$ corresponding to the screening criteria. Thus, it is possible that the screening criteria in the NRC PTS Rule are not appropriate for all PWR vessels.

Another indication that the specific screening criteria may not be appropriate for all PWR vessels is the presumed existence of a few PWR vessels that have high concentrations of $\mathrm{Cu}$ and $\mathrm{Ni}$ in the plate regions, as opposed to or in addition to the welds, and a few that have their axial welds in adjacent shell courses aligned rather than staggered. This latter situation can result in greater surface length for flaws than assumed and thus a greater potential for radial propagation, while the former situation increases the probability of vessel failure as a result of more flaws in a critical region (larger critical region). Of course, these vessels can be identified and the screening criteria modified, if necessary. It may not be as easy, however, to identify those vessels, if any, that otherwise are not appropriately limited in operating lifetime by the existing screening criteria.

\section{Discussion and Conclusions}

1. Based on results of the IPTS study, it appears that the NRC PTS Rule screening criteria are appropriate for Calvert Cliffs and H. B. Robinson, but they may not be adequate for all U.S. PWR vessels, particularly those that may have high copper in the plate material and those that have axial welds aligned. 
2. The number of flaws per vessel is the single largest uncertainty in the study. More extensive investigations to reduce the uncerainty in flaw density could have a substantial impact on the best-estimate and mean values of $\Phi(F)$.

3. The dominant transients are very different for each of the three plants analyzed, and small differences in plant design can have significant effects for a given category of transient. Thus, generic studies can be misleading.

4. The IPTS study focused on the safety aspect of the PTS issue; that is, breaching of the vessel. There is a purely economic issue as well. Many of the transients (relatively low-pressure transients) resulted in crack arrest, following initiation, at depths that presumably would make continued operation inadvisable without repair. If repairs are impractical, perhaps all transients resulting in crack initiation should be considered in evaluating the life of the vessel.

5. Since the time that the IPTS study was completed (1985), new information has been developed that could change the calculated values of $\Phi(F)$ substantially, and presumably this information can and will be used in future IPTS studies. The new information includes, but is not necessarily limited to the following:

a. Most of the dominant transients for Calvert Cliffs (small-break LOCAs) include primary-side coolant-flow stagnation. A more recent evaisation of flow conditions for these transients indicates that stagnation probably would not actually take place. ${ }^{25}$ This change in the analysis would reduce $\Phi(F)$ for Calven Cliffs by a factor of $\sim 10$.

b. Stresses associated with propagation of circumferentially-oriented flaws may be significantly greater than considered for the case of severe flow channeling 
beneath an inlet nozzle (plumes developed during stagnation flow and with injection of emergency core coolant). If severe channeling exists, circumferential flaws could be bigger contributors to $\Phi(F)$, and this would tend to increase $\Phi(F)$.

c. Most of the initial flaws that resulted in vessel failure may be shallow enough ( 8 to $15 \mathrm{~mm}$ ) to have effective fracture toughness values that are substantially greater than the normal plain-strain values that were used in the study. 8,26 Furthermore, results of large-scale thermal-shock experiments ${ }^{27}$ indicate that the plain-strain fracture toughness is greater than specified for the IPTS study. Use of higher values in the IPTS studies would decrease $\Phi(F)$.

d. Experiments with clad plates ${ }^{12,13}$ and irradiation of cladding 14 indicate that cladding may not be as beneincial as anticipated. In the IPTS studies, the fracture toughness of the cladding was assumed to be the same as for the base material. There are indications that in a highly-irradiated state, the toughness could be less. This would increase $\Phi(F)$.

e. PTS experiments conducted with large steel vessels indicate that flaws located in low-upper-shelf weld material may experience significant ductile tearing prior to cleavage. ${ }^{28}$ Inclusion of this phenomenon in an IPTS study would tend to increase $\Phi(F)$ because in effect, the initial flaw depth would be greater than assumed.

f. The radiation-damage trend curve $[\triangle R T N D T=f(C u, N i, F)]$ has been updated since the IPTS study was conducted. The most recent version ${ }^{29}$ predicts larger values of $\triangle R T N D T$ for some vessels, but it has no influence on $\Phi(F)$, if RTNDT is used as the independent variable as opposed to $\mathrm{Cu}, \mathrm{Ni}, \mathrm{F}$, and $\mathrm{RTNDT}_{\mathrm{O}}$. It is more appropriate to use the latter parameters as independent variables, and, when 
this is done, variations in the trend curve do make a difference in $\Phi(F) .^{8}$ The difference can be either plus or minus, depending on specific values of the independent variables and characterisics of the transients.

g. Crack-at ${ }_{1}$ est toughness data have been obtained that extend the arrest-toughness curve well above the limit imposed by the ASME Code 30,31 and used in the IPTS study. In principle, inclusion of the new data will decrease $\Phi(F) .31$

\section{References}

1. G. D. Whitman, Historical Summary of the Heavy-Section Steel Technology Program and Some Kelated Activities in Light-Water Reactor Pressure Vessel Safety Research, NUREG/CR-4489 (ORNL-6259), March 1986.

2. R. D. Cheverton, S. K. Iskander, and G. D. Whitman, "The Integrity of PWR Pressure Vessels During Overcooling Accidents," Proceedings of the International Meeting on Thermal Nuclear Reactor Safety, NUREG/CR-0027, Vol. 1, Feb. 1983, pp. $421-430$.

3. USNRC PTS Rule, 10 CFR 50, Item 50.61, July 23, 1985 (50FR29937).

4. F. A. Simonen et al., Reactor Pressure Vessel Failure Probability Following Through-Wall Cracks Due to Pressurized Thermal Shock Events, NUREG/CR-4483 (PNL-5727), April 1986.

5. Regulatory Guide 1.154, "Format and Content of Plant-Specific Pressurized Thermal Shock Safety Analysis Reports for Pressurized Water Reactors," U.S. Nuclear Regulatory Commission, Office of Nuclear Regulatory Research, January 1987.

6. T. J. Burns et al., Pressurized Tirsmal Shock Evaluation of the Oconee-1 Nuclear Power Plant, NUREG/CR-3770 (ORNL/TM-9176), May 1986.

7. D. L. Selby et al., Pressurized Thermal Shock Evaluation of the Calvert Cliffs Unit 1 Nuclear Power Plant, NUREG/CR-4022 (ORNL/TM-9408), Sept. 1985.

8. D. L. Selby et al., Pressurized Thermal Shock Evaluation of the H. G. Robinson Unit 2 Nuclear Power Plant, NUREG/CR-4183 (ORNL/TM-9567), Vols. 1 and 2, Sept. 1985.

9. S. T. Rolfe and J. M. Barsom, Fracture and Fatigue Control in Structures, Applications of Fracture Mechanics, Prentice-Hall, Inc., 1977. 
10. R. D. Cheveron and D. G. Ball, OCA-P, A Deterministic and Probabilistic FractureMechanics Code for Application to Pressure Vessels, NUREG/CR-3618 ORNL5991), Oak Ridge Natl. Lab., Oak Ridge, Tenn. (May 1984).

11. D. G. Ball and R. D. Cheverton, Adaptation of OCA-P, A Probabilistic FractureMechanics Code to a Personal Computer, NUREG/CR-4468 (ORNL/CSD/TM-233), Jan. 1986.

12. S. K. Iskander, G. C. Robinson, and C. B. Oland, "Flaw Behavior in Mechanically Loaded Clad Plates," 1.. artin Marietta Energy Systems, Inc., Oak Ridge Natl. Lab., to be published in Nuclear Engineering and Design.

13. R. D. Cheverton et al., "Thermal Shock Experiments with Flawed Clad Cylinders," Martin Marietta Energy Systems, Inc., Oak Ridge Natl. Lab., to he published in Nuclear Engineering and Design.

14. F. M. Haggag, W. R. Corwin, and R. K. Nanstad, "Effects of Irradiation on the Fracture Properties of Stainless Steel Weld Overlay Cladding," Martin Marietta Energy Systems, Inc., Oak Ridge Natl. Lab., to be published in Nuclear Engineering and Design.

15. W. Marshall et al., An Assessment of the Integrity of PWR Pressure Vessels, UKAEA Study Group Reports, October 1976 and March 1982.

16. A. D. Swain and H. E. Guttmann, Handbook of Human Reliability Analysis with Emphasis on Nuclear Power Plant Applications, Final Report, NUREG/CR-1278, Sandia National Laboratory, August 1983.

17. C. D. Fletcher et al., RELAP5 Thermal-Hydraulic Analysis of Pressurized Thermal Shock Sequences for the Oconee-1 Pressurized Water Reactor, EGG-NSMD-63343, July 1983.

18. C. D. Fletcher et al., Thermal-Hydraulic Analyses of Pressurized Thermal Shock Sequences for the H. B. Robinson Unit 2 Pressurized Water Reactor, EG\&G Idaho, Inc., idaho Falls, Idaho, NUREG/CR-3977, April 1985.

19. Safety Code Development Group, TRAC-PF1: An Advanced Best-Estimate Computer Program for Pressurized Water Reactor Analysis, Los Alamos National Laboratory, NUREG/CR-3567, February 1984.

20. J. E. Koenig, G. D. Spriggs, and R. C. Smith, TRAC Analyses of Potential Overcooling Transients at Calvert Cliffs-1 for PTS Risk Assessment, Los Alamos National Laboratory, NUREG/CR-4109, February 1985.

21. T. G. Theofanous, P. Gherson, H. P. Nourbakhsh, and K. Iyer, Decay of Buoyancy Driven Stratified Layers with Applications to PTS, NUREG/CR-3700, February 1984. 
22. H. P. Nourbakhsh and T. G. Theofanous, REMIX: A Computer Program for Temperature Transients Due to HPI at Stagnated Loop Flow, NUREG/CR-3701, May 1984.

23. M. W. Fanning and P. H. Rothe, Transient Cooldown in a Model Cold LRG and Downcomer, EPRI Report P.P-2122-3, May 1983.

24. F,. J. Daly and M. D. Torrey, SOLA-PTS: A Transient, Three-Dimensional Algorithm for Fluid-Thermal Mixing and Wall Heat Transfer in Complex Geometries, Los Alamos National Laboratory, NUREG/CR-3822, July 1984.

25. T. G. Theofanous, J. L. La Chance, and K. A. Williams, "Thermal Hydraulics of Small-Break Loss-of-Coolant Accidents Relative to Pressurized Thermal Shock," Nuclear Science and Engineering, Vol. 102, No. 1, pp. 74-100, May 1989.

26. W. A. Sorem, S. T. Rolfe, and R. H. Dodds, Jr., "The Effects of Crack Depth on Elastic-Plastic CTOD Fracture Toughness," Welding Research Council Bulletin, Bulletin 351, February 1990.

27. R. D. Cheverton, S. K. Iskander, and D. G. Ball, "Review of Pressurized-WaterReactor-Related Thermal-Shock Studies," pp. 752-766 in Fracture Mechanics: Nineteenth Symposium, ASTM STP 969, T. A. Cruse, Ed., American Society for Testing and Materials, Philadelphia, 1988.

28. R. H. Bryan et al., Pressurized-Thermal Shock Test of 6-in.-Thick Pressure Vessels. PTSE-2: Investigation of Low Tearing Resistance and Warm Prestressing, NUREG/ CR-4888 (ORNL-6377), Martin Marietta Energy Systems, Inc., Oak Ridge Natl. Lab., 1987.

29. Regu!atory Guide 1.99, Rev. 2, U.S. Nuclear Regulatory Commission, Office of Nuclear Regulatory Research, May 1988.

30. T. U. Marston (Ed.), Flaw Evaluation Procedures: ASME Section XI, EPRI NP719-S12, Electric Power Research Institute, August 1975.

31. T. L. Dickson, Inclusion of Unstable Ductile Tearing and Extrapolated Crack-Arrest Toughness Data in PWR Vessel Integrity Assessment, NUREG/CR-5473 (ORNL/TM-11450), Martin Marietta Energy Systems, Inc., Oak Ridge Natl. Lab., in publication.

\section{DISCLAIMER}




\section{Acknowledgements}

The authors wish to acknowledge contributions made to the IPTS Program by the Idaho National Engineering Laboratory, Los Alamos National Laboratory, Science Applications International Corporation, Purdue University, Decision Analysis Unit of the London School of Economics and Political Science, and Human Reliability Associates (Lancasinire). The Program was managed and directed by the Oak Ridge National Laboratory. Technical monitor for the Nuclear Regulatory Commission was Carl E. Johnson, Jr. 
Table 1. Material properties, fluences, and surface areas used in LEFM analysis of Calvert Cliffs Unit 1 reactor vessel

\begin{tabular}{|c|c|c|c|c|c|c|}
\hline \multicolumn{2}{|c|}{$\begin{array}{c}\text { Section } \\
\text { Identification }\end{array}$} & \multicolumn{2}{|c|}{ Chemistry } & \multirow{2}{*}{$\begin{array}{c}\text { Neutron fluence } \\
\text { at inner surface } a \\
32 \mathrm{EFPY} \\
\left(10^{19} \mathrm{n} / \mathrm{cm}^{2}\right)\end{array}$} & \multirow{2}{*}{$\begin{array}{l}\text { RTNDT }_{0} \\
\left({ }^{\circ} \mathrm{C}\right)\end{array}$} & \multirow{2}{*}{$\begin{array}{l}\text { Surface } \\
\text { area } b \\
\left(\mathrm{~m}^{2}\right)\end{array}$} \\
\hline Form & Number & (wt\%) & $(w t \%)$ & & & \\
\hline Plate & $\begin{array}{l}\text { D-7206-1 } \\
\text { D-7206-2 } \\
\text { D-7206-3 } \\
\text { D-7207-1 } \\
\text { D-7207-2 } \\
\text { D-7207-3 }\end{array}$ & $\begin{array}{l}0.11 \\
0.12 \\
0.12 \\
0.13 \\
0.11 \\
0.11\end{array}$ & $\begin{array}{l}0.55 \\
0.64 \\
0.64 \\
0.54 \\
0.56 \\
0.53\end{array}$ & $\begin{array}{l}6.06 \\
6.06 \\
6.06 \\
6.06 \\
6.06 \\
6.06\end{array}$ & $\begin{array}{l}-7 \\
-34 \\
-12 \\
-12 \\
-12 \\
-7\end{array}$ & $\begin{array}{r}11.3 \\
11.3 \\
11.3 \\
9.6 \\
9.6 \\
9.6\end{array}$ \\
\hline Axial weld & $\begin{array}{l}2-203 A \\
2-203 B, C \\
3-203 A \\
3-203 B, C\end{array}$ & $\begin{array}{l}0.21 \\
0.21 \\
0.20 \\
0.20\end{array}$ & $\begin{array}{l}0.87 \\
0.87 \\
0.71 \\
0.71\end{array}$ & $\begin{array}{l}6.06 \\
3.03 \\
6.06 \\
3.03\end{array}$ & $\begin{array}{l}-49 \\
-49 \\
-49 \\
-49\end{array}$ & $\begin{array}{l}0.12 \\
0.23 \\
0.10 \\
0.19\end{array}$ \\
\hline $\begin{array}{l}\text { Circumferential } \\
\text { weld }\end{array}$ & $9-203$ & 0.24 & 0.18 & 6.06 & -62 & 0.64 \\
\hline
\end{tabular}

$a_{\text {Maximum value in section. }}$

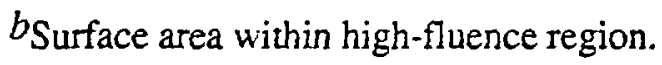


Table 2. Dominant transients ${ }^{a}$

\begin{tabular}{|c|c|c|}
\hline Oconee $b$ & Calvert Cliffs & $\mathrm{HBY}-\mathrm{HYPO}{ }^{b}$ \\
\hline Reactor trip ${ }^{c}(42 \%)$ & Small-break LOCA ${ }^{d}(91 \%)$ & Reactor trip (88\%) \\
\hline Large SLB $(14 \%)$ & Small SI $\mathrm{B}^{d}(9 \%)$ & 3 STM PORVS $(36 \%)$ \\
\hline Small-break LOCA $(12 \%)$ & Residuals $\left[\Phi(\mathrm{E})<10^{-7}\right](<1 \%)$ & 2 STM PORVS (24\%) \\
\hline Excess MFW (9\%) & & $\geq 3$ SDVs $(15 \%)$ \\
\hline Loss of MFW (9\%) & & Others $(13 \%)$ \\
\hline Inadvertent SI (5\%) & & Small-break LOCA (3\%) \\
\hline SGTR $(2 \%)$ & & Large SLB $(2 \%)$ \\
\hline Small SLB (2\%) & & Small SLB (1\%) \\
\hline Residuals (5\%) & & Residuals $\left[\Phi(\mathrm{E})<10^{-7}\right](5 \%)$ \\
\hline
\end{tabular}

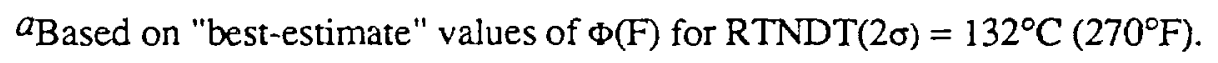

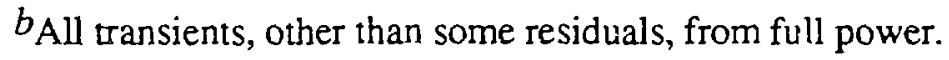

${ }^{c}$ Spurious trips followed by (1) excessive steam flow (TBVS and/or SSRVs stuck open) and/or (2) excessive feed water flow.

$d_{\text {Hot zero power. }}$ 